\title{
Carbon fiber reinforced thermoplastic composites from acrylic polymer matrices: Interfacial adhesion and physical properties
}

\author{
H. Kishi", N. Nakao, S. Kuwashiro, S. Matsuda \\ Graduate School of Engineering, University of Hyogo, 2167, Shosha, Himeji, 671-2201 Hyogo, Japan
}

Received 15 October 2016; accepted in revised form 14 December 2016

\begin{abstract}
Acrylic polymers have high potential as matrix polymers for carbon fiber reinforced thermoplastic polymers (CFRTP) due to their superior mechanical properties and the fact that they can be fabricated at relatively low temperatures. We focused on improving the interfacial adhesion between carbon fibers (CFs) and acrylic polymers using several functional monomers for co-polymerization with methyl methacrylate (MMA). The copolymerized acrylic matrices showed good adhesion to the CF surfaces. In particular, an acrylic copolymer with acrylamide (AAm) showed high interfacial adhesive strength with CFs compared to pure PMMA, and a hydroxyethyl acrylamide (HEAA) copolymer containing both amide and hydroxyl groups showed high flexural strength of the CFRTP. A 3 mol\% HEAA-copolymerized CFRTP achieved a flexural strength almost twice that of pure PMMA matrix CFRTP, and equivalent to that of an epoxy matrix CFRP.
\end{abstract}

Keywords: polymer composites, thermoplastic, carbon fiber, acryl, copolymer

\section{Introduction}

Carbon fiber reinforced thermoplastic composites (CFRTP) are lightweight materials that display high strength, high elastic modulus, and high potential for low-cost manufacturing or secondary fabrication, which are attractive characteristics for many industrial applications [1-5]. Several types of thermoplastic polymers have been researched as matrices of CFRTPs.

One class of promising thermoplastic polymers for CFRTP is polyamides. Polyamide 6 [6-8], polyamide $6.6[9,10]$, and polyamide 12 [11] were general purpose polyamides applied for CFRTPs. In general, polyamides are semi-crystalline polymers having strong intermolecular attractive force due to the hydrogen bonding. Especially, polyamide 6 and polyamide 6.6 have relatively high modulus of elasticity, around $3 \mathrm{GPa}$. The modulus of elasticity is important characteristic for the matrix polymers to achieve high strength of the CFRTP. Though the amide groups generate strong interaction between polymer chains, they have hydrophilic property simultaneously. Therefore, polyamides have high water uptake nature. The high water absorption plasticized the polymer matrix and degraded the fiber/matrix adhesion of the composites in the wet condition [9]. This was reported even in the case of composites using polyarylamide having hydrophobic aromatic structure in the polymer backbone [12].

Polypropylene [13-15] is also a semi-crystalline polymer that has been applied for CFRTPs. Unlike polyamides, polypropylene is a polymer with low water absorption. Though polypropylene is a typical commodity polymer, the drawback as the matrix polymer for CFRTP is relatively low elastic modulus less than $2 \mathrm{GPa}$ and the low adhesive properties. The low adhesive property with carbon fiber/filler could be somewhat improved by blending of maleic-anhydride

${ }^{*}$ Corresponding author, e-mail: kishi@eng.u-hyogo.ac.jp (C) BME-PT 
modified copolymer $[14,15]$. However, the low elastic modulus would be fateful nature unless the polymer backbone structure is changed. Because, the room temperature is higher than the $T_{\mathrm{g}}$ of the polypropylene (around $0{ }^{\circ} \mathrm{C}$ ).

Moreover, aromatic thermoplastic polymers, such as polycarbonate $[16,17]$, polybutylene terephthalate [18], polyethersulfone [19-21], polyetherimide [19, $22,23]$, polyimide $[24,25]$, polyetheretherketone [19, 26-29] and polyphenylenesulfide [30-32] have also been studied for high performance carbon fibers (CFs)/polymer matrix composites. In general, the aromatic polymers have high temperature resistance, high modulus of elasticity, and water resistance. However, the interfacial structure and the improved adhesion between the matrix polymers and carbon fibers should be important to realize the high potential of the composites. Polybutylene terephthalate [18], polyetheretherketone [19, 26-30] and polyphenylenesulfide [31-33] are semi-crystalline thermoplastic polymer matrices. The crystal size, the crystal structure, and the crystallinity would be influenced by the surface of carbon fibers as crystalization-nucleus, as well as by the cooling rate and the annealing in the fabrication process. In other words, the mechanical properties of these CFRTPs using semi-crystalline polymers would be sensitive for the crystallization kinetics in the fabrication process.

In these backgrounds, acrylic polymers, which are highly transparent amorphous polymers, have not been utilized as matrix polymers for CFRTPs. However, many types of acrylic copolymer can be designed using commercially available monomers to meet diverse requirements, such as high elastic modulus and low water absorption. Therefore, they have high potential as the thermoplastic matrices of CFRTPs that exhibit good mechanical properties. Moreover, the acrylic polymers can be fabricated at relatively low temperature, and no crystallization occurs due to the amorphous nature. Therefore, the mechanical properties would be robust for the change of fabrication temperature.

Meanwhile, it should be necessary to have good interfacial adhesion between CFs and matrix polymers for produce the high performance CFRTPs. Numerous methods for surface treatment of CFs, such as chemical modification [24, 34], electrochemical oxidation [35-41], and plasma treatment [16, 17, 19, 21$23,29]$ have been studied to assure good interfacial adhesion. The basic idea of the CF surface modification is as follows. One is to increase the affinity or reactivity with the matrix polymers, and improve adhesive strength physico-chemically or chemically. The other is to increase micro irregularities of the CF surface, aiming at increasing in the adhesion area and improving in the adhesive strength via the anchor effect. The numerous methods for CF modification above-mentioned pursued either or both of these.

Takahagi and Ishitani at the Toray Research Center reported that the major functional groups introduced onto the surface of CFs by an electrochemical oxidation treatment were hydroxyl and carboxyl groups $[40,41]$. Typically, the surface of commercially available CFs is designed for interaction with epoxy polymers and not for acrylic polymers such as polymethyl methacrylate (PMMA). Interfacial adhesion between CFs and acrylic polymers is the key to realize the potential of acrylic CFRTPs, as well as the cases of other thermoplastic polymers. In this study, we focused on improving the interfacial adhesion between acrylic polymers and $\mathrm{CFs}$ using several functional monomers for co-polymerization with methyl methacrylate (MMA), using commercially available CFs. The effect of the chemical structures of the functional monomers on the physical properties of the resulting acrylic CFRTPs was examined from the viewpoint of interfacial adhesive strengths, flexural strengths, and behavior under wet conditions.

\section{Experimental procedure \\ 2.1. Materials}

The matrix polymer of CFRTPs was polymerized basically from methyl methacrylate (MMA, produced by SIGMA-ALDRICH Japan). Functional monomers, particularly acrylamide (AAm, produced by SIGMAALDRICH Japan), 2-hydroxyethyl acrylate (HEA, produced by KOHJIN, Japan), and hydroxyethyl acrylamide (HEAA, produced by KOHJIN, Japan), were co-polymerized at $60^{\circ} \mathrm{C}$ with the MMA, using 2,2'azobis(4-methoxy-2,4-dimethylvaleronitrile), produced by Wako Pure Chemical Industries, Ltd., Japan, as an initiator for the polymerization. The chemical structures of the monomers are shown in Figure 1. The weight-average molecular mass for the acrylic polymers was controlled in the range 300000400000 ; this was evaluated using size exclusion chromatography (JASCO SEC, PU-2080 HPLC system, 


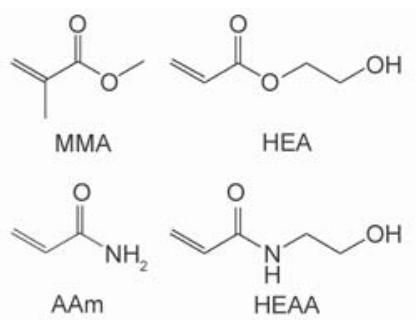

Figure 1. Chemical structures of acrylic monomers

Japan, using tetrahydrofuran as the solvent). The average molecular mass was calibrated based on monodisperse polystyrene standards.

CF plain-woven fabric CO6343B consists of T3003K (manufactured by TORAY Industries, Inc., Japan) was utilized as reinforcement fibers for the acrylic CFRTPs. The areal density of the carbon fabric was $198 \mathrm{~g} / \mathrm{m}^{2}$. CF fabric/acrylic polymer prepregs were produced using the plain-woven $\mathrm{CF}$ fabric and the acrylic monomers. First, the CF fabric was placed in an aluminum mold, and the properly weighed acrylic monomer mixture was poured into the mold. Then, the monomers were polymerized in the $\mathrm{CF}$ fabric at $60^{\circ} \mathrm{C}$ for 2 hours, and the prepreg sheet was obtained. The prepreg sheet was sandwiched between aluminum plates, and was placed in an oven at $100^{\circ} \mathrm{C}$ for 5 hours and $150^{\circ} \mathrm{C}$ for 4 hours. The fiber volume content $\left(V_{\mathrm{f}}\right)$ of the CF fabric prepreg sheet was 50 vol\%.

\subsection{Fabrication of CFRTP laminates}

The CF fabric prepregs containing the acrylic polymers were stacked, and placed between aluminum plates. The 2-ply prepregs were stacked for fabricating specimens for lap-shear evaluation. On the other hand, the 8-ply prepregs were stacked for flexural evaluation. CFRTP laminates were fabricated from the stacked prepregs using a hot-pressing machine at $220^{\circ} \mathrm{C}$ for 10 minutes under a pressure of $0.64 \mathrm{MPa}$. After that, the CFRTPs with aluminum plates were moved to a cold-pressing machine, and cooled down until ambient temperature.

\subsection{Evaluation of mechanical properties of CFRTP laminates}

The shear strength of the interface between the CFs and the matrix polymers was evaluated using a lapshear configuration in a tensile strain rate of $0.5 \mathrm{~mm} / \mathrm{min}$ at $23^{\circ} \mathrm{C}$, using a testing machine (Shimadzu AUTOGRAPH AGS-J, Japan). The thickness of the 2-ply laminates was $0.65 \mathrm{~mm}$. The lap area had a length of $6 \mathrm{~mm}$, and a width of $6 \mathrm{~mm}$.
The flexural strength of the CFRTP laminates was measured using a three-point bending configuration in a cross-head speed of $5 \mathrm{~mm} / \mathrm{min}$ at $23^{\circ} \mathrm{C}$, using a testing machine (Shimadzu AUTOGRAPH AGSJ, Japan). The load capacity was $10 \mathrm{kN}$. The specimen length was $80 \mathrm{~mm}$, the width was $12 \mathrm{~mm}$, the thickness was $2 \mathrm{~mm}$, and the span length for the three-point bending was $64 \mathrm{~mm}$. For evaluation of the influence of water absorption, the CFRTP laminates were pre-soaked in water at $36^{\circ} \mathrm{C}$ for 220 hours. The edges of the pre-soaked specimens were free as cut.

\subsection{Evaluation of mechanical properties of acrylic matrix polymers}

Specimens with a length of $50 \mathrm{~mm}$, a width of $10 \mathrm{~mm}$, and a thickness of $2 \mathrm{~mm}$ were machined from $2 \mathrm{~mm}$-thick polymer plates made using a hot-pressing machine. Flexural stress-strain curves for several acrylic polymers were evaluated in three-point bending configuration with a cross-head speed of $5 \mathrm{~mm} / \mathrm{min}$ at $23{ }^{\circ} \mathrm{C}$, using a testing machine (Shimadzu AUTOGRAPH AGS-J, Japan). The span length for the threepoint bending was $28 \mathrm{~mm}$. For evaluation of the influence of water absorption, the weight increase of the specimens was measured after pre-soaking in water at $36^{\circ} \mathrm{C}$ until 220 hours. The edges of the presoaked specimens were free as cut.

\subsection{Microscopic observation}

\subsubsection{Scanning electron microscopy}

The fracture surfaces of the cured resins were observed by scanning electron microscopy (SEM: KEYENCE VE-9800, Japan). The samples were mounted on brass stubs and coated with a thin layer of gold using an ion sputter coater (JEOL JFC1100E, Japan).

\subsubsection{Optical microscopy}

After the flexural test, the specimens were removed for side-view observation using optical microscopy (OM: KEYENCE Digital microscope VHX-200, Japan) in reflected light mode. The specimens were cut using a diamond saw, and the sides were polished petrographically and observed.

\section{Results and discussion}

\subsection{Acrylic CFRTP vs. epoxy CFRP}

Figure 2 shows flexural stress-strain curves for an epoxy CFRP and an acrylic (PMMA) CFRTP. The 


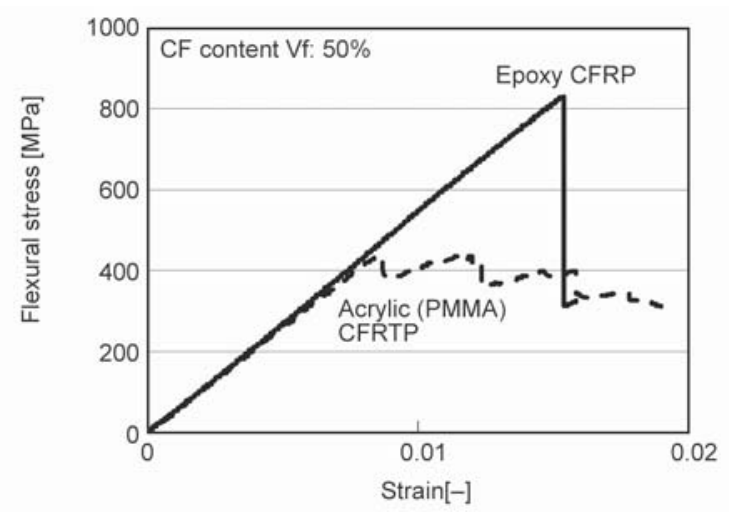

Figure 2 Flexural stress-strain curves of epoxy CFRP and acrylic (PMMA) CFRP

flexural strength of the epoxy CFRP was $830 \mathrm{MPa}$, while that of the PMMA CFRTP was $450 \mathrm{MPa}$, corresponding to $54 \%$ of the strength of the epoxy CFRP. For the epoxy CFRP, the initial fracture occurred at the tensile side of the bending specimens. In contrast, fracturing of the PMMA CFRTP occurred at the compression side of the specimens. In addition, the stressstrain curves for the PMMA CFRTPs deviated from a linear stress-strain relationship by around $300 \mathrm{MPa}$. Figure 3 shows a comparison of the fracture surfaces of the PMMA CFRTP and the epoxy CFRP. In the epoxy CFRP, there was good adhesion between the matrix resins and the CF surface; in contrast, for the fracture surface of PMMA CFRTPs, the CFs were not covered with the matrix polymers. Adhesion between the CFs and PMMA was poor, and it was therefore confirmed that interfacial adhesion is a key factor in improving the mechanical properties of acrylic CFRTPs.

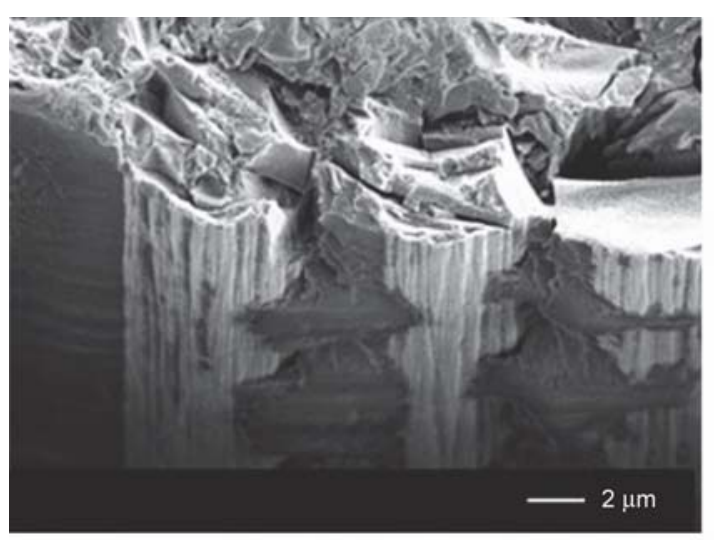

a)

\subsection{Interfacial adhesion and mechanical properties of acrylic CFRTPs using functional copolymers as matrices}

It was reported that electrochemical oxidized CFs have small numbers of functional groups, particularly carboxylic groups and hydroxyl groups, on the surfaces $[40,41]$. The CF surfaces were expected to have positive interactions, such as hydrogen bonding and dipole interactions, with the copolymerized acrylic polymers.

Figure 4 shows the effect of functional monomers co-polymerized with MMA on the flexural properties of acrylic CFRTPs ( $V_{\mathrm{f}}: 50$ vol\%). Although all of the monomers had some effect on the flexural strength of the CFRTP laminates, co-polymerization with HEAA caused the greatest improvement in strength. A CFRTP with a PMMA/3 mol\% HEAA copolymer matrix had a flexural strength of 810 $950 \mathrm{MPa}$, which was almost twice the value of

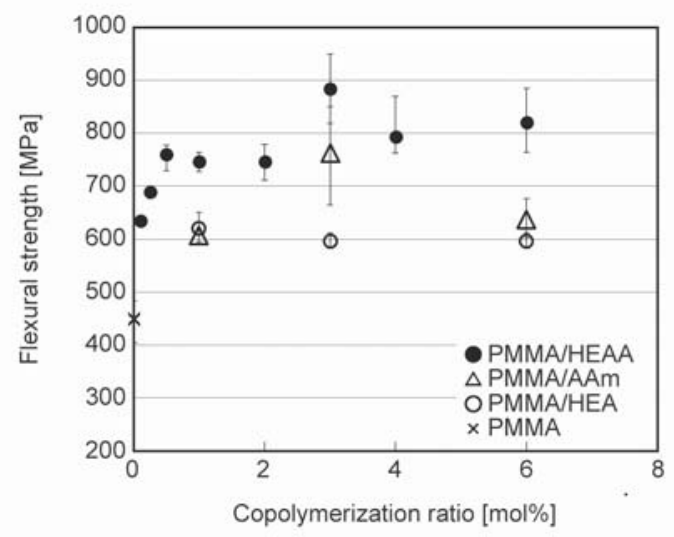

Figure 4. Effect of co-polymerization on the flexural strengths of acrylic CFRTPs

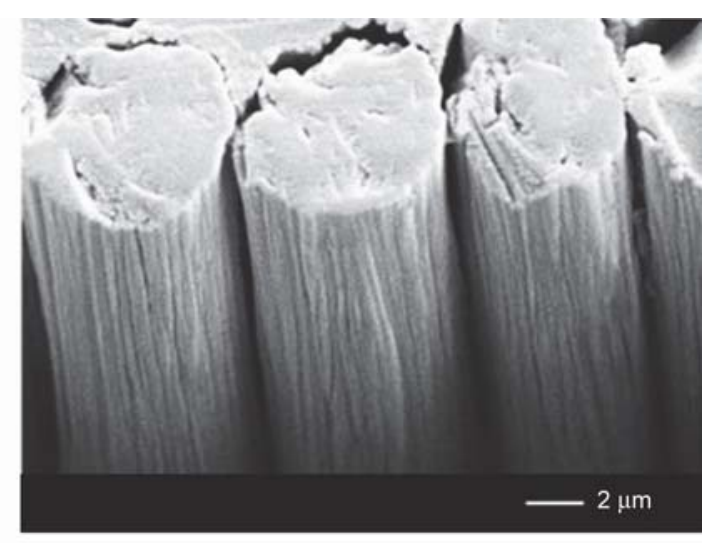

b)

Figure 3. Fracture surfaces of epoxy CFRP and acrylic (PMMA) CFRP, a) epoxy CFRP, b) acrylic (PMMA) CFRP 


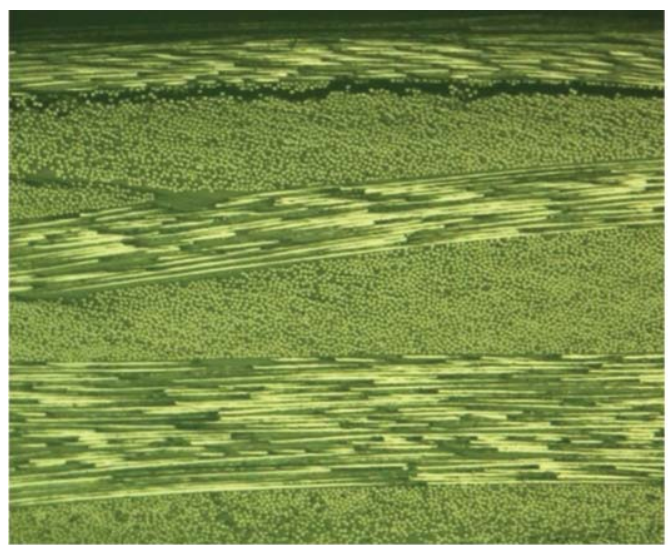

a)

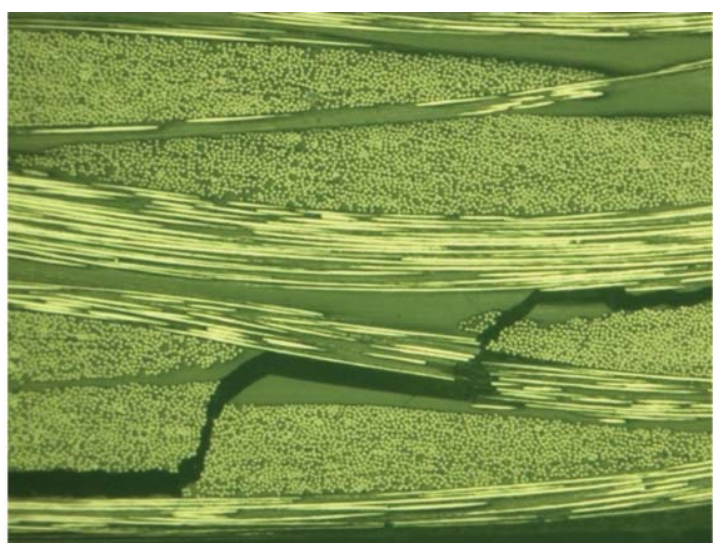

b)

Figure 5. Side view of fractured acrylic CFRTP specimens after flexural tests, a) compressive area of CF/PMMA, b) tensile area of $\mathrm{CF} / \mathrm{P}(\mathrm{MMA} / 3 \mathrm{~mol} \% \mathrm{HEAA})$

$450 \mathrm{MPa}$ for the pure PMMA matrix CFRTP. It can be seen from Figure 4 that even a small amount of HEAA copolymerization, less than $1 \mathrm{~mol} \%$, had a considerable effect in improving the strength of CFRTPs. A key point that should be noted is the change in the fracture mode for CFRTP. Delamination occurred on the compressive side of flexural specimens of pure PMMA matrix CFRTP (Figure 5a). In contrast, for HEAA copolymerized CFRTPs, the main fracture
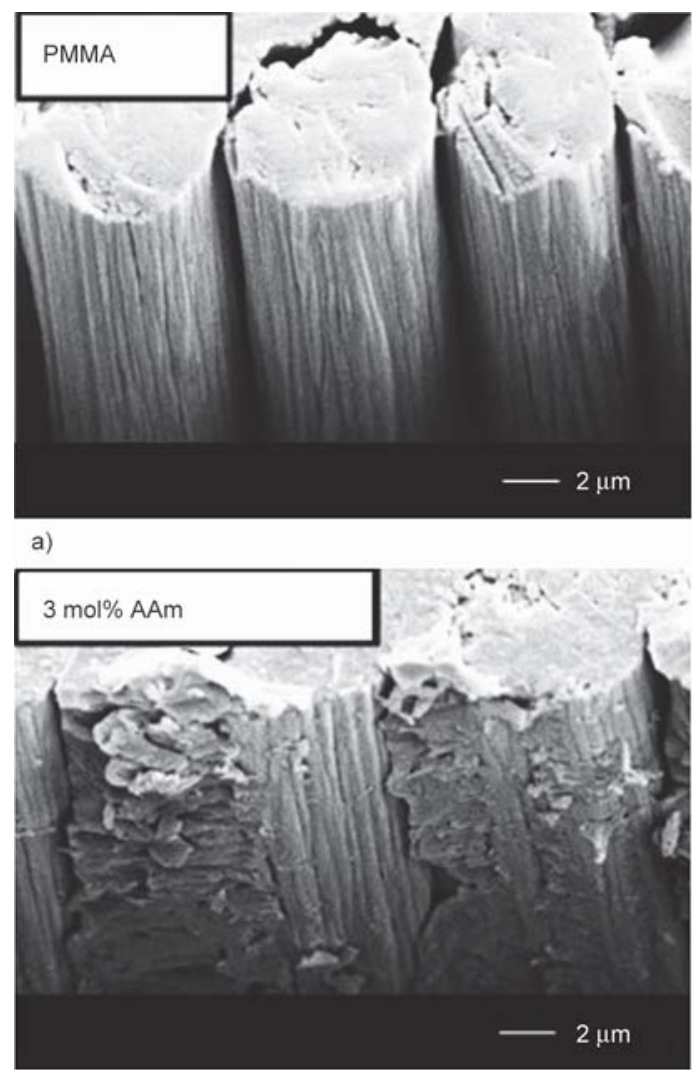

c) mode was CF breakage on the tensile side of the flexural specimens (Figure 5b). It may be presumed that increased interfacial adhesion prevented delamination of the laminates, which changed the fracture mode, and this resulted in a dramatic increase in the flexural strength of the CFRTPs.

Figure 6 shows the fracture surfaces of several acrylic CFRTPs. Copolymerization with HEA seemed to have only a small effect on adhesion to the CFs, but

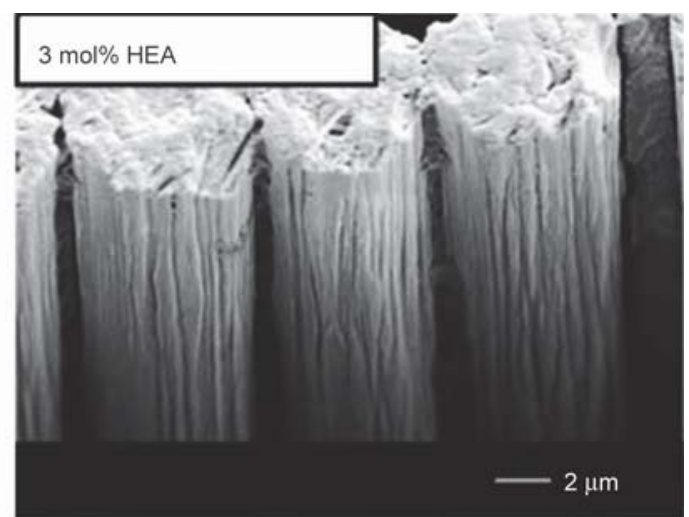

b)

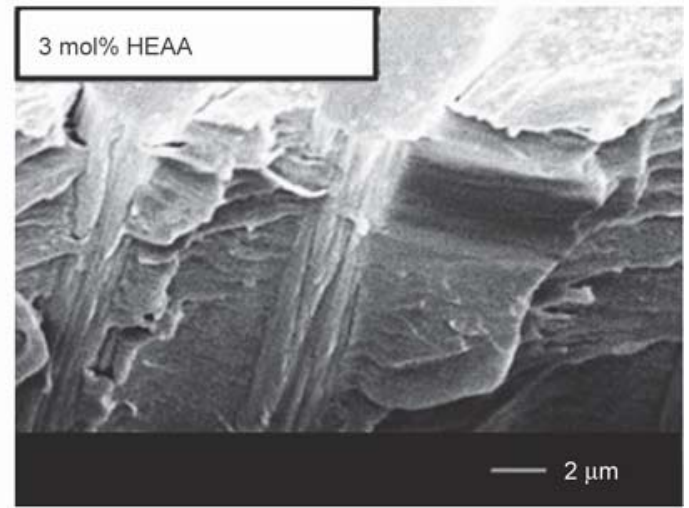

d)

Figure 6. images of fractured surfaces of CFRTP specimens in the flexural tests, a) PMMA, b) P(MMA/3 mol\%HEA), c) $\mathrm{P}(\mathrm{MMA} / 3$ mol\%AAm), d) P(MMA/3 mol\%HEAA) 


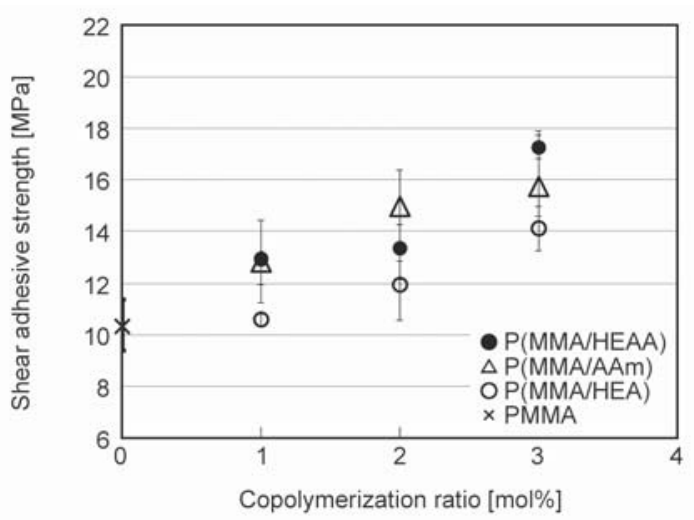

Figure 7 Effect of copolymerization on the shear adhesive strengths of acrylic CFRTPs

copolymerization with HEAA and AAm had a considerable effect. In order to quantify the increased adhesive strength of the interface between the matrix polymers and the CFs, the shear adhesive strength of the CFRTP laminates was evaluated. Figure 7 shows the effect of co-polymerization of functional monomers on the shear adhesive strength of the CFRTPs. Copolymerization with HEAA and AAm had a clear effect on the shear adhesive strength of acrylic polymers. As shown in Figure 8, there was a good relationship between the shear adhesive strength and the flexural strength of the acrylic CFRTPs. The data showed that the source of the high flexural strength of the modified acrylic CFRTP was the increased shear strength of the interface between the

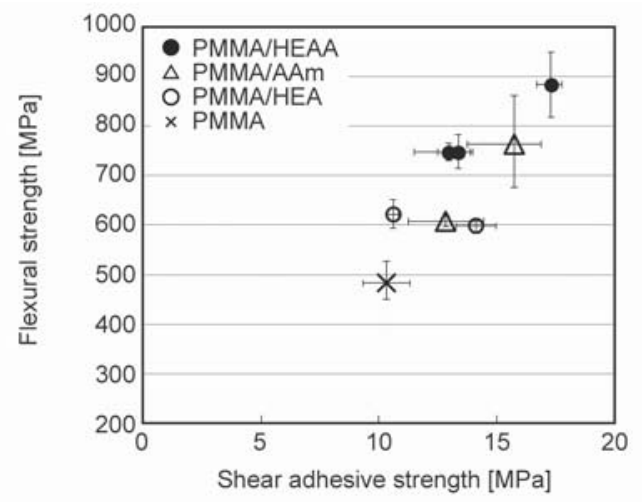

Figure 8. Relationship between the shear adhesive strengths and the flexural strengths of acrylic CFRTPs
CFs and the acrylic copolymers, $\mathrm{P}(\mathrm{MMA} / \mathrm{HEAA})$ and $\mathrm{P}(\mathrm{MMA} / \mathrm{AAm})$.

It is known that the flexural strength of CFRPs is affected not only by the interfacial strength but also by the elastic modulus of the matrix polymer. Specifically, a large elastic modulus in the matrix polymer results in high compressive strength and high flexural strength of the CFRP [42]. Therefore, the effect of co-polymerization on the elastic modulus of acrylic matrix polymers must be also examined. Table 1 shows the elastic moduli and $T_{\mathrm{g}}$ of the acrylic copolymers. Copolymerization with AAm, HEA and HEAA gave a positive effect on the elastic moduli of acrylic polymers. And, Figure 9 shows the effect of the elastic modulus of acrylic copolymers on the flexural strength of the corresponding acrylic CFRTPs. Increasing the elastic modulus in the matrix polymers had a positive effect on the flexural strength of the acrylic CFRTPs. However, among matrix polymers with the same elastic modulus, the flexural strength of the resulting CFRTPs was different. HEAA copolymerization had the greatest effect on the flexural strength of the acrylic CFRTP. Therefore, it can be concluded that the adhesive strength of the interface between the CFs and the acrylic copolymers was the main contributor to increased flexural strength in the laminates. This was due to the fracture mode change from delamination (on the compression side) to tensile breakage of the CFs for the flexural specimens.

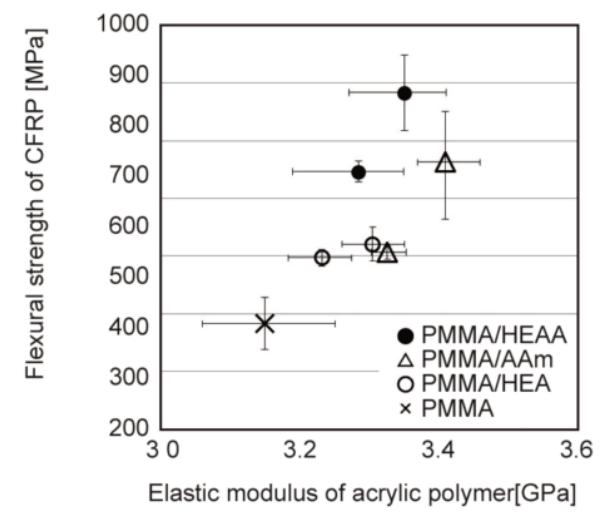

Figure 9. Relationship between the elastic moduli of acrylic copolymers and the flexural strengths of the acrylic CFRTPs

Table 1. Moduli of elasticity and $T_{\mathrm{g}} \mathrm{s}$ of acrylic co-polymers

\begin{tabular}{|c|c|c|c|c|c|c|c|}
\hline \multirow{2}{*}{ mol\% of co-monomer } & PMMA & \multicolumn{2}{|c|}{ P(MMA/AAm) } & \multicolumn{2}{|c|}{ P(MMA/HEA) } & \multicolumn{2}{|c|}{ P(MMA/HEAA) } \\
\cline { 2 - 8 } & $\mathbf{0}$ & $\mathbf{1}$ & $\mathbf{3}$ & $\mathbf{1}$ & $\mathbf{3}$ & $\mathbf{1}$ & $\mathbf{3}$ \\
\hline$E[\mathrm{GPa}]$ & 3.15 & 3.33 & 3.41 & 3.23 & 3.30 & 3.28 & 3.35 \\
\hline$T_{\mathrm{g}}\left[{ }^{\circ} \mathrm{C}\right]$ & 105 & 105 & 105 & 104 & 102 & 105 & 105 \\
\hline
\end{tabular}




\subsection{Performance of acrylic CFRTPs using functional copolymers under wet conditions}

In general, copolymerization with functional monomers with an amide structure confers hydrophilic properties on the copolymers. Figure 10 shows the amount of water absorption by both pure PMMA and PMMA 3 mol\% HEAA copolymer at $36^{\circ} \mathrm{C}$. The copolymer absorbed more water than the pure PMMA. This increase in water absorption may result in deterioration of the mechanical properties of the CFRTPs from the point of view of both the elastic modulus of the matrix polymer and the interfacial adhesive strength. Therefore, the mechanical properties of acrylic CFRTPs were examined after 220 hours water absorption at $36^{\circ} \mathrm{C}$, and the results are shown in Figure 11.

The flexural strength of both the PMMA CFRTP and 3 mol\% HEAA copolymer CFRTP decreased after water absorption. However, the fraction of flexural

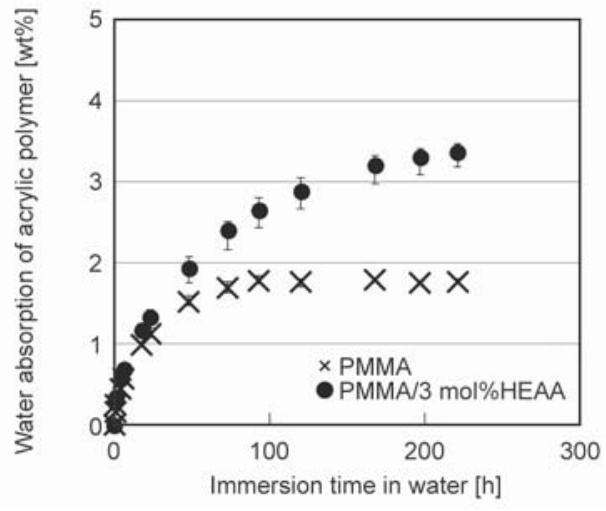

Figure 10. Water absorption of PMMA and P(MMA/3 mol\% HEAA)

P(MMA/3 mol\%HEAA) CFRTP before water absorption P(MMA/3 mol\%HEAA) CFRTP after water absorption Pure PMMA matrix CFRTP before water absorption

-.-- Pure PMMA matrix CFRTP after water absorption

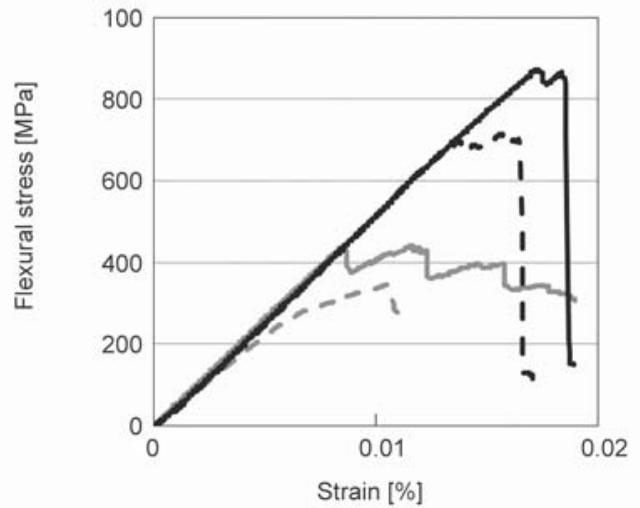

Figure 11. Flexural stress-strain curves of $\mathrm{P}(\mathrm{MMA} / 3 \mathrm{~mol} \%$ HEAA) matrix CFRTP and PMMA CFRTP - before/after water absorption

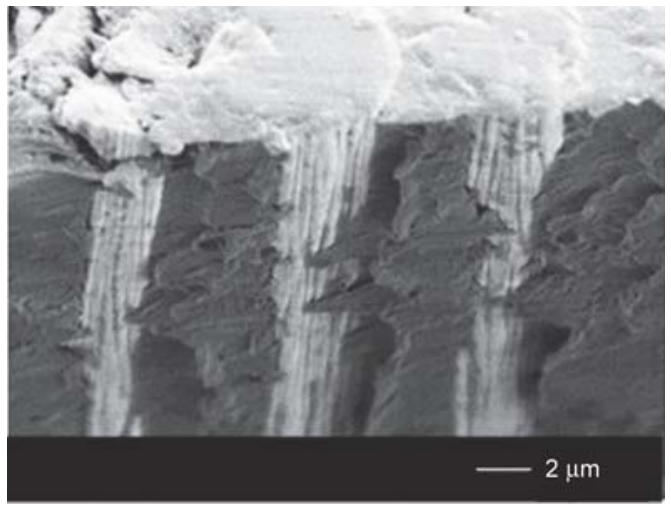

Figure 12. Fracture surface of $\mathrm{P}(\mathrm{MMA} / 3 \mathrm{~mol} \%$ HEAA) CFRTP after water absorption

strength remaining was about $80 \%$ for both CFRTPs, although the $3 \mathrm{~mol} \%$ HEAA copolymer absorbed more water than PMMA. Figure 12 shows the fracture surface of the 3 mol\% HEAA copolymer CFRTP after water absorption, at which point it showed good adhesion to the CFs. Thus, high interfacial adhesion and flexural strength were retained for the $3 \mathrm{~mol} \%$ HEAA copolymer CFRTP after water absorption. The $20 \%$ decrease in flexural strength was thought to have been caused by the decrease in the elastic modulus of the matrix polymers after water absorption.

\section{Conclusions}

In order to improve the interfacial adhesive properties of acrylic polymers with $\mathrm{CFs}$, several functional monomers were co-polymerized with methyl methacrylate (MMA) in order to fabricate acrylic CFRTPs. It was observed that the functional copolymer matrices adhered well to the CF surfaces. In particular, a hydroxyethyl acrylamide (HEAA) copolymer containing both amide and hydroxyl groups showed high adhesive strength with CFs, which resulted in high flexural strength for the resulting CFRTP laminates, even under wet conditions. The flexural strength of CFRTPs fabricated from HEAA co-polymerized acrylic matrices was almost twice that of pure PMMA CFRTPs, and equivalent to that of an epoxy CFRP. This was thought to be due to a fracture mode change from delamination on the compression side to tensile breakage of the CFs in the flexural specimens. Therefore, it can be concluded that the increased interfacial adhesive strength of HEAA co-polymerized acrylic copolymers with CFs contributed to the high flexural strength of the laminates by preventing delamination. 


\section{Acknowledgements}

The authors would like to thank those at TORAY COATEX CO., LTD, especially Mr. Satoshi Ogasa and Mr. Kazuhiko Kominami, for preparation of some of the materials and for helpful discussions.

\section{References}

[1] Chang I. Y., Lees J. K.: Recent development in thermoplastic composites: A review of matrix systems and processing methods. Journal of Thermoplastic Composite Materials, 1, 277-296 (1988).

https://doi.org/10.1177/089270578800100305

[2] Ó’Brádaigh C. M., Mallon P. J.: Effect of forming temperature on the properties of polymeric diaphragm formed thermoplastic composites. Composites Science and Technology, 35, 235-255 (1989).

https://doi.org/10.1016/0266-3538(89)90037-7

[3] Mallon P. J., Ó’Brádaigh C. M., Pipes R. B.: Polymeric diaphragm forming of complex-curvature thermoplastic composite parts. Composites, 20, 48-56 (1989). https://doi.org/10.1016/0010-4361(89)90682-4

[4] Ageorges C., Ye L., Hou M.: Advances in fusion bonding techniques for joining thermoplastic matrix composites: A review. Composites Part A: Applied Science and Manufacturing, 32, 839-857 (2001). https://doi.org/10.1016/S1359-835X(00)00166-4

[5] Rezaei F., Yunus R., Ibrahim N. A., Mahdi E. S.: Development of short-carbon-fiber-reinforced polypropylene composite for car bonnet. Polymer-Plastics Technology and Engineering, 47, 351-357 (2008).

https://doi.org/10.1080/03602550801897323

[6] Djumaev A., Takahashi K.: Effect of moisture absorption on damping performance and dynamic stiffness of NY-6/CF commingled yarn composite. Journal of Materials Science, 29, 4736-4741 (1994).

https://doi.org/10.1007/BF00356517

[7] Choi N. S., Yamaguchi H., Takahashi K.: Fracture behavior of unidirectional commingled-yarn-based carbon fiber/polyamide 6 composite under three-point bending. Journal of Composite Materials, 30, 760-784 (1996). https://doi.org/10.1177/002199839603000701

[8] An H. J., Kim J. S., Kim K-Y., Lim D. Y., Kim D. H.: Mechanical and thermal properties of long carbon fiberreinforced polyamide 6 composites. Fibers and Polymers, 15, 2355-2359 (2014).

https://doi.org/10.1007/s12221-014-2355-5

[9] Mohd Ishak Z. A., Berry J. P.: Hygrothermal aging studies of short carbon fiber reinforced nylon 6.6. Journal of Applied Polymer Science, 51, 2145-2155 (1994). https://doi.org/10.1002/app.1994.070511306

[10] Karsli G. N., Ozkan C., Aytac A., Deniz V.: Effects of sizing materials on the properties of carbon fiber-reinforced polyamide 6,6 composites. Polymer Composites, 34, 1583-1590 (2013).

https://doi.org/10.1002/pc.22556
[11] Czigany T., Karger-Kocsis J.: A comparison of the mechanical behaviour of weft-knitted glass and carbon fiber fabric-reinforced polyamide- 12 composites produced with commingled staple yarns. Polymers and Polymer Composites, 9, 491-497 (2001).

[12] Czigany T., Mohd Ishak Z. A., Karger-Kocsis J.: On the failure mode in dry and hygrothermally aged short fiber-reinforced injection-molded polyarylamide composites by acoustic emission. Applied Composite Materials, 2, 313-326 (1995).

https://doi.org/10.1007/BF00568767

[13] Dean D. M., Marchione A. A., Rebenfeld L., Register R. A.: Flexural properties of fiber-reinforced polypropylene composites with and without a transcrystalline layer. Polymers for Advanced Technologies, 10, 655-668 (1999).

https://doi.org/10.1002/(SICI)1099-1581(199911)10:11<655:: AID-PAT919>3.0.CO;2-\#

[14] Szentes A., Varga Cs., Horváth G., Bartha Z., Haspel H., Szél J., Kukovecz A.: Electrical resistivity and thermal properties of compatibilized multi-walled carbon nanotube/polypropylene composites. Express Polymer Letters, 6, 494-502 (2012).

https://doi.org/10.3144/expresspolymlett.2012.52

[15] Arao Y., Yumitori S., Suzuki H., Tanaka T., Tanaka K., Katayama T.: Mechanical properties of injection-molded carbon fiber/polypropylene composites hybridized with nanofillers. Composites Part A: Applied Science and Manufacturing, 55, 19-26 (2013).

https://doi.org/10.1016/j.compositesa.2013.08.002

[16] Montes-Morán M. A., Martínez-Alonso A., Tascón J. M. D., Paiva M. C., Bernardo C. A.: Effects of plasma oxidation on the surface and interfacial properties of carbon fibres/polycarbonate composites. Carbon, 39, 1057-1068 (2001).

https://doi.org/10.1016/S0008-6223(00)00220-7

[17] Montes-Morán M. A., van Hattum F. W. J., Nunes J. P., Martínez-Alonso A., Tascón J. M. D., Bernardo C. A.: A study of the effect of plasma treatment on the interfacial properties of carbon fibre-thermoplastic composites composites. Carbon, 43, 1795-1799 (2005).

https://doi.org/10.1016/j.carbon.2005.02.005

[18] Yu T., Wu C. M., Chang C. Y., Wang C. Y., Rwei S. P.: Effects of crystalline morphologies on the mechanical properties of carbon fiber reinforcing polymerized cyclic butylene terephthalate composites. Express Polymer Letters, 6, 318-328 (2012).

https://doi.org/10.3144/expresspolymlett.2012.35

[19] Tiwari S., Sharma M., Panier S., Mutel B., Mitschang P., Bijwe J.: Influence of cold remote nitrogen oxygen plasma treatment on carbon fabric and its composites with specialty polymers. Journal of Materials Science, 46, 964-974 (2011).

https://doi.org/10.1007/s10853-010-4847-z 
[20] Yuan H., Zhang S., Lu C., He S., An F.: Improved interfacial adhesion in carbon fiber/polyether sulfone composites through an organic solvent-free polyamic acid sizing. Applied Surface Science, 279, 279-284 (2013). https://doi.org/10.1016/j.apsusc.2013.04.085

[21] Sharma M., Bijwe J., Singh K.: Studies for wear property correlation for carbon fabric-reinforced PES composites. Tribology Letters, 43, 267-273 (2011). https://doi.org/10.1007/s11249-011-9805-7

[22] Tiwari S., Bijwe J., Panier S.: Adhesive wear performance of polyetherimide composites with plasma treated carbon fabric. Tribology International, 44, 782-788 (2011).

https://doi.org/10.1016/j.triboint.2011.01.009

[23] Tiwari S., Bijwe J., Panier S.: Influence of plasma treatment on carbon fabric for enhancing abrasive wear properties of polyetherimide composites. Tribology Letters, 41, 153-162 (2011).

https://doi.org/10.1007/s11249-010-9694-1

[24] Zhang X. R., Pei X. Q., Wang Q. H.: The effect of fiber oxidation on the friction and wear behaviors of shortcut carbon fiber polyimide composites. Express Polymer Letters, 1, 318-325 (2007).

https://doi.org/10.3144/expresspolymlett.2007.45

[25] Zhang X. R., Zhao P., Pei X. Q., Wang Q. H., Jia Q.: Flexural strength and tribological properties of rare earth treated short carbon fiber/polyimide composites. Express Polymer Letters, 1, 667-672 (2007). https://doi.org/10.3144/expresspolymlett.2007.91

[26] Seferis J. C.: Polyetheretherketone (PEEK): Processing-structure and properties studies for a matrix in high performance composites. Polymer Composites, 7, 158 169 (1986). https://doi.org/10.1002/pc. 750070305

[27] Velisaris C. N., Seferis J. C.: Crystallization kinetics of polyetheretherketone (PEEK) matrices. Polymer Engineering and Science, 26, 1574-1581 (1986). https://doi.org/10.1002/pen.760262208

[28] Ostberg G. M. K., Seferis J. C.: Annealing effects on the crystallinity of polyetheretherketone (PEEK) and its carbon fiber composite. Journal of Applied Polymer Science, 33, 29-39 (1987) https://doi.org/10.1002/app.1987.070330103

[29] Yoon H., Takahashi K.: Mode I interlaminar fracture toughness of commingled carbon fibre/PEEK composites. Journal of Materials Science, 28, 1849-1855 (1993). https://doi.org/10.1007/BF00595757

[30] Sharma M., Bijwe J., Mitschang P.: Wear performance of PEEK-carbon fabric composites with strengthened fiber-matrix interface. Wear, 271, 2261-2268 (2011). https://doi.org/10.1016/j.wear.2010.11.055

[31] Kenny J. M., Maffezzoli A.: Crystallization kinetics of poly(phenylene sulfide) (PPS) and PPS/carbon fiber composites. Polymer Engineering and Science, 31, 607 614 (1991).

https://doi.org/10.1002/pen.760310812
[32] Jiang Z., Gyurova L. A., Schlarb A. K., Friedrich K., Zhang Z.: Study on friction and wear behavior of polyphenylene sulfide composites reinforced by short carbon fibers and sub-micro $\mathrm{TiO}_{2}$ particles. Composites Science and Technology, 68, 734-742 (2008). https://doi.org/10.1016/j.compscitech.2007.09.022

[33] Liu B., Liu Z., Wang X., Zhang G., Long S., Yang J.: Interfacial shear strength of carbon fiber reinforced polyphenylene sulfide measured by the microbond test. Polymer Testing, 32, 724-730 (2013). https://doi.org/10.1016/j.polymertesting.2013.03.020

[34] Severini F., Formaro L., Pegoraro M., Posca L.: Chemical modification of carbon fiber surfaces. Carbon, $\mathbf{4 0}$, 735-741 (2002). https://doi.org/10.1016/S0008-6223(01)00180-4

[35] Yue Z. R., Jiang W., Wang L., Gardner S. D., Pittman Jr. C. U.: Surface characterization of electrochemically oxidized carbon fibers. Carbon, 37, 1785-1796 (1999). https://doi.org/10.1016/S0008-6223(99)00047-0

[36] Pittman Jr. C. U., Jiang W., Yue Z. R., Gardner S., Wang L., Toghiani H., Leon y Leon C. A.: Surface properties of electrochemically oxidized carbon fibers. Carbon, 37, 1797-1807 (1999). https://doi.org/10.1016/S0008-6223(99)00048-2

[37] Gulyás J., Földes E., Lázár A., Pukánszky B.: Electrochemical oxidation of carbon fibers: Surface chemistry and adhesion. Composites Part A: Applied Science and Manufacturing, 32, 353-360 (2001). https://doi.org/10.1016/S1359-835X(00)00123-8

[38] Liu X., Yang C., Lu Y.: Contrastive study of anodic oxidation on carbon fibers and graphite fibers. Applied Surface Science, 258, 4268-4275 (2012). https://doi.org/10.1016/j.apsusc.2011.12.076

[39] Qian X., Wang X., Ouyang Q., Chen Y., Yan Q.: Effect of ammonium-salt solutions on the surface properties of carbon fibers in electrochemical anodic oxidation. Applied Surface Science, 259, 238-244 (2012). https://doi.org/10.1016/j.apsusc.2012.07.025

[40] Takahagi T., Ishitani A.: XPS studies by use of the digital difference spectrum technique of functional groups on the surface of carbon fiber. Carbon, 22, 43-46 (1984). https://doi.org/10.1016/0008-6223(84)90131-3

[41] Ishitani A.: Application of X-ray photoelectron spectroscopy to surface analysis of carbon fiber. Carbon, 19, 269-275 (1981). https://doi.org/10.1016/0008-6223(81)90072-5

[42] Johnston N. J.: Synthesis and toughness properties of resins and composites. in 'Proceedings of ACEE Composite Structures Technology Conference, Seattle, USA' 75-95 (1984). 